Cite this: Soft Matter, 2014, 10, 2188

\title{
Multistimuli responsive organogels based on a reactive azobenzene gelator $\uparrow$
}

\begin{abstract}
Runmiao Yang, ${ }^{* a b}$ Shuhua Peng ${ }^{c}$ and Timothy C. Hughes ${ }^{\star b}$
A reactive azobenzene based super organogelator was found to rapidly and reversibly transform a range of hydrophobic solvents from gels to solutions upon changes in temperature, light and shear force. More specifically they formed gels at concentrations as low as $0.08 \mathrm{wt} \%$. Upon heating, exposure to UV light, or application of shear, the $\pi-\pi$ bonding was disrupted which resulted in a rapid drop of both modulus and viscosity. This was confirmed by ${ }^{1} \mathrm{H}$ NMR, SAXS, and rheological measurements. Although many examples of organogelators are known in the literature, this is the first time that a reactive group, a benzoyl chloride, has been incorporated in a supramolecular organogel structure. Moreover, this group is available for subsequent synthetic modifications. The presence of benzoyl chloride groups showed a remarkable effect on the formation and properties of the gels. Compared with other approaches, this strategy is advantageous in terms of structural design since it not only produces a multi-responsive soft material but also allows facile modifications which may expand the applications of organogels to other fields.
\end{abstract}

Received 18th December 2013 Accepted 17th January 2014

DOI: $10.1039 / c 3 s m 53145 g$

www.rsc.org/softmatter attention, since it is a non-contaminating stimulus that provides a broad range of tunable parameters, e.g., wavelength, intensity, and duration, to manipulate the rheological properties of photoresponsive systems. ${ }^{\mathbf{1 0 - 1 2}}$

Photo-active groups such as diarylethene substituted butadienes, ${ }^{13} \mathrm{Fe}(\mathrm{II})$ triazoles, ${ }^{14}$ merocyanines, ${ }^{15}$ and azobenzenes ${ }^{\mathbf{1 6 - 1 8}}$ have been successfully introduced to LMOGs. Through these groups the chemical nature of the gel can change the selfassembly structure upon exposure to different wavelengths of light. LMOGs incorporating the azobenzene moiety exhibit trans-to-cis photoisomerisation behavior which influences the mechanical properties of the gel upon UV/visible light irradiation. ${ }^{19,20}$ Recently, multistimuli responsive organogels containing azobenzene have also been reported. For example, $\mathrm{Liu}^{\mathbf{2 1}}$ designed and synthesized an organogelator (Azo-G3) whose selfassembly behavior and gel formation ability was investigated in detail. Meanwhile, Wang ${ }^{22}$ and Zhang $^{23}$ designed and studied multistimuli responsive organogels featuring electroactive tetrathiafulvalene (TTF) and photoresponsive azobenzene groups. Although azobenzene gelators containing relatively inert functional groups, such as alkyl chains, benzene rings, ethers and esters, have been widely reported, ${ }^{24-26}$ to the best of our knowledge, multistimuli-responsive organogelators comprising reactive functional groups which are capable of forming stable gels have not been previously described. Typically, LMOGs form gels at concentrations higher than $1.0 \mathrm{wt} \%$ which may limit their commercial applicability. Zinic et al., defined 'super gelator' as a class of gelators with critical gelation concentration (CGC) below $0.1 \mathrm{wt} \% .^{27}$ To date relatively few azobenzene based super gelators have been reported..$^{\mathbf{8 1 2}, 27}$

\footnotetext{
${ }^{a}$ Department of Material Engineering, Jiangsu University of Technology, Changzhou, 213001, China. E-mail: yangrunmiao@jsut.edu.cn; Tel: +86-519-86953291

${ }^{b}$ CSIRO Materials Science and Engineering, Bayview Avenue, Melbourne, VIC 3168, Australia. E-mail: tim.hughes@csiro.au; Tel: +61-3-95452503

${ }^{c}$ Department of Chemical and Biomolecular Engineering, University of Melbourne, Melbourne, VIC 3010, Australia

$\dagger$ Electronic supplementary information (ESI) available: Synthetic procedures and characterization data for new compounds; the thermal behaviours, viscosity and morphologies of the gels in different temperature; modulus and SAXS data on exposure to UV light. See DOI: 10.1039/c3sm53145g
} 
Reactive groups which are incorporated into LMOGs not only act as an effective unit to control the morphology of their selfassembly but also play an important role in forming an organogel. More importantly, they may provide a bridge to introduce further functionalities through synthetic elaboration and expand the applications of such smart materials. ${ }^{28-30}$ With those objectives in mind, we designed and synthesized a new low molecular weight organogelator $\left(\mathrm{C}_{8}\right.$-Azo-TPC), composed of an alkyl chain, an azobenzene unit, and a reactive benzoyl chloride moiety. The azobenzene unit provides the possibility of multiresponsiveness while the benzoyl chloride moiety enables facile functionalization of the gelator.

\section{Experimental section}

Synthesis of $\mathrm{C}_{8}$-Azo-TPC, preparation, and characterization are described in detail in the ESI. $\dagger$ All chemicals were purchased from Sigma-Aldrich and Merck and used without further purification. No purification was performed on the solvents except for the tetrahydrofuran (THF) and toluene, which was taken from an Innovative Technologies, Inc., solvent purification system. All the chemicals were characterized by ${ }^{1} \mathrm{H}$ and ${ }^{13} \mathrm{C}$ NMR spectroscopy on a $400 \mathrm{MHz}$ Bruker Ultrashiled Spectrometer (Bruker, Germany) in $\mathrm{CDCl}_{3}$. Accurate mass spectra were obtained on a Thermo Scientific $Q$ Exactive FTMS, employing ASAP probe. Photoisomerization of $\mathrm{C}_{8}$-Azo-TPC was measured on a Cary 50-Bio UV-Vis Spectrophotometer (Varian) against a background of solvent in a quartz cuvette. Trans to cis isomerisation was induced by an EXFO Acticure 4000 light source via a liquid light-guide working at $365 \mathrm{~nm}$ wavelength. The UV light intensity was about $3.8 \mathrm{~mW} \mathrm{~cm}^{-2}$. Cis to trans isomerisation was induced by visible light at $12.1 \mathrm{~mW} \mathrm{~cm}^{-2}$. UV-vis data was collected every 30 seconds. Rheology was conducted using an ARES photo-rheometer (TA Instruments, USA) connected to an EXFO Acticure 4000 UV light source ( $365 \mathrm{~nm}, 200 \mathrm{~mW} \mathrm{~cm}^{-2}$ ) and quartz-halogen visible light source (>540 nm, $38 \mathrm{~mW} \mathrm{~cm}^{-2}$ ) via liquid light-guide. A Peltier temperature controller was also connected to the rheometer to maintain the temperature. POM was conducted using a Nikon Eclipse 80i. SAXS experiments were performed at the Australian Synchrotron on the small/wide angle X-ray scattering beamline working at $12.0 \mathrm{keV}$.

\section{Determination of critical gelation concentration (CGC)}

Typically, $5 \mathrm{mg}$ of gelator was mixed with $0.5 \mathrm{~g}$ of solvent. The mixture was heated until the organogelator dissolved and a clear solution was obtained. The solutions were then cooled to room temperature and gel formation was determined by inverting the vials.

\section{Results and discussion}

The synthesis of the 4-chlorocarbonyl-benzoic acid 4 - $\left(4^{\prime \prime}\right.$-octyloxy-phenylazo)-benzyl ester $\left(\mathrm{C}_{8}\right.$-Azo-TPC, (4)) started from phenol and $p$-ethylcarboxylate analine in a 4 step procedure outlines in Scheme 1. The synthetic details and characterization data are provided in the ESI. $\dagger$

The gelation ability of $\mathrm{C}_{8}$-Azo-TPC was evaluated in various organic solvents by inversion test of cooled solutions. The gelation results with critical gelation concentrations are presented in Table 1 . Stable gels were formed when the $\mathrm{C}_{8}$-Azo-TPC was mixed with nonpolar solvents such as alkanes while it was soluble in polar solvents, such as chloroform, acetone and THF. Apart from gels formed in DMF and petroleum fuel, $\mathrm{C}_{8}$-Azo-TPC was able to form gels at concentrations less than $0.1 \mathrm{wt} \%$, indicating its 'super gelator' properties. ${ }^{31-33} \mathrm{C}_{8}$-Azo-TPC formed

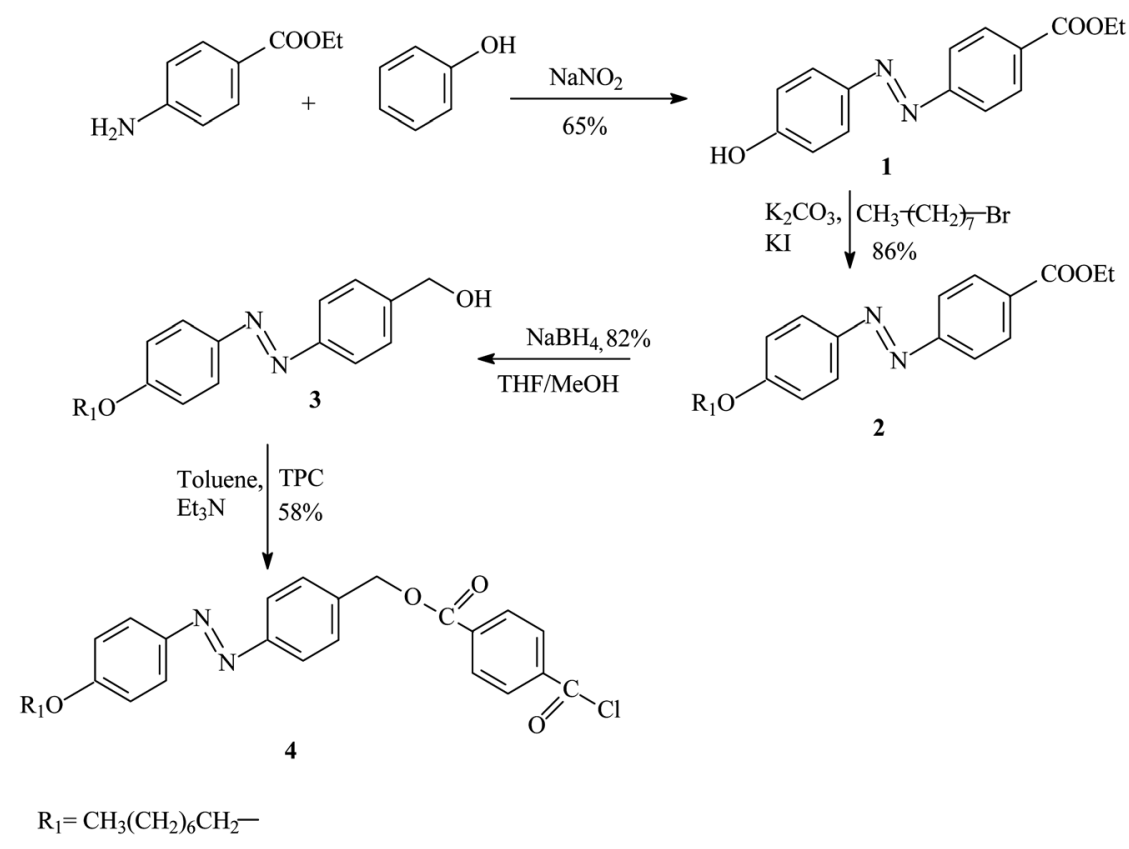

Scheme 1 Synthesis of $\mathrm{C}_{8}$-Azo-TPC. 
Table 1 Gelation ability of $\mathrm{C}_{8}$-Azo-TPC in various solvents at room temperature ${ }^{a}$

\begin{tabular}{|c|c|c|c|c|c|}
\hline Solvent & State & CGC (wt\%) & Solvent & State & CGC (wt\%) \\
\hline Olive oil & $\mathrm{S}$ & - & Carbon tetrachloride & $\mathrm{S}$ & - \\
\hline Petroleum fuel & $\mathrm{G}$ & 2.4 & Engine oil & S & - \\
\hline Benzene & S & - & $n$-Heptane & G & 0.4 \\
\hline Ethyl acetate & $\mathrm{S}$ & - & $n$-Decane & G & 0.1 \\
\hline Dichloromethane & $\mathrm{S}$ & - & $n$-Octane & G & 0.1 \\
\hline Toluene & $\mathrm{S}$ & - & Cyclohexane & $\mathrm{G}$ & 0.5 \\
\hline Chloroform & $\mathrm{S}$ & - & $n$-Dodecane $/$ EtOAc $=10 / 1$ & G & 0.2 \\
\hline Petroleum benzine & G & 0.4 & $n$-Heptane/EtOAc $=10 / 1$ & G & 0.4 \\
\hline
\end{tabular}

${ }^{a}$ CGC, critical gelation concentration, the minimum concentration necessary for gelation of solvents; S, soluble; G, gel; PG, partial gel.

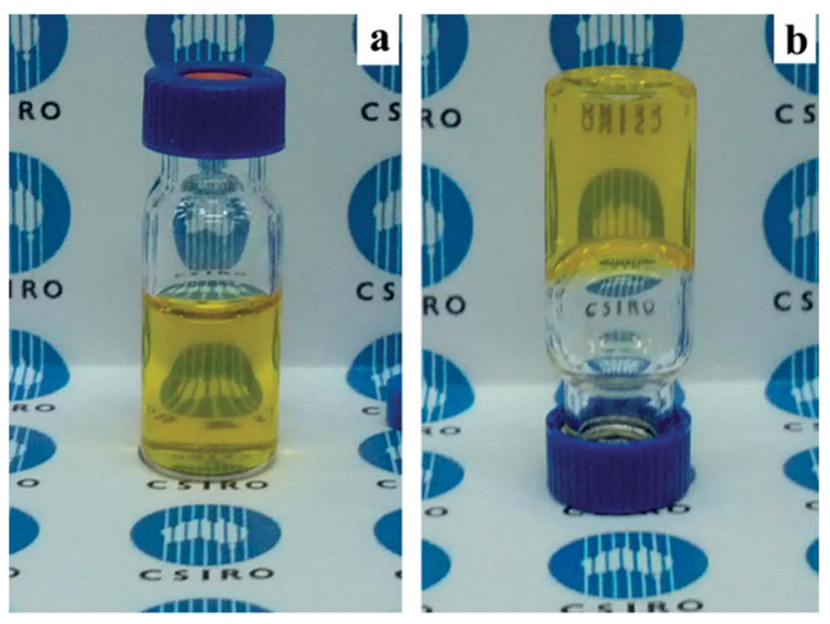

Fig. 1 Photographs of the azobenzene sol $\left(60^{\circ} \mathrm{C}\right)$ and gel $\left(20^{\circ} \mathrm{C}\right)$ in $n-$ dodecane at $0.1 \mathrm{wt} \%$.

a translucent yellow gel in alkane or mixed solvents at very low concentrations with CGCs as low as $0.08 \mathrm{wt} \%$, directly comparable to the best know azobenzene gelators. ${ }^{8,21}$ Fig. 1 shows photographs of the azobenzene sol $\left(60^{\circ} \mathrm{C}\right)$ and gel $\left(20^{\circ} \mathrm{C}\right)$ in $n$-dodecane at $0.1 \mathrm{wt} \%$. After cooling, it formed a light transparent yellow gel, through which the background could be clearly observed (Fig. 1). The intensity of the color of the gels and solution depended on the concentration of the $\mathrm{C}_{8}$-Azo-TPC used.

\section{Thermal induced sol/gel transitions}

Representative photographs of sol-gel process are shown in Fig. 2. An orange colored solution in $n$-dodecane $(1.0 \mathrm{wt} \%)$ was formed by heating. Upon cooling, the yellow colored gel could be regenerated within 3 minutes (or faster if actively cooled) (Fig. S12†). This reversible gel-sol phase transition could be repeated several times as demonstrated by the reversible changes in optical transmission upon repeated heating and cooling cycles between 20 and $60{ }^{\circ} \mathrm{C}$ (Fig. 3). Even after several months, the gel remained stable. A rheological study showed a reversible change in viscosity with change in temperature (Fig. 4). Initially, at $20^{\circ} \mathrm{C}$ the sample was a viscous liquid with a $\left|\eta^{*}\right| \sim 210 \mathrm{~Pa}$ s. immediately following the increase in temperature, a dramatic decrease of viscosity was observed. Specifically, the viscosity reached a new steady state of $\left|\eta^{*}\right| \sim 5$ Pa s at $55^{\circ} \mathrm{C}$ which was maintained until the temperature began

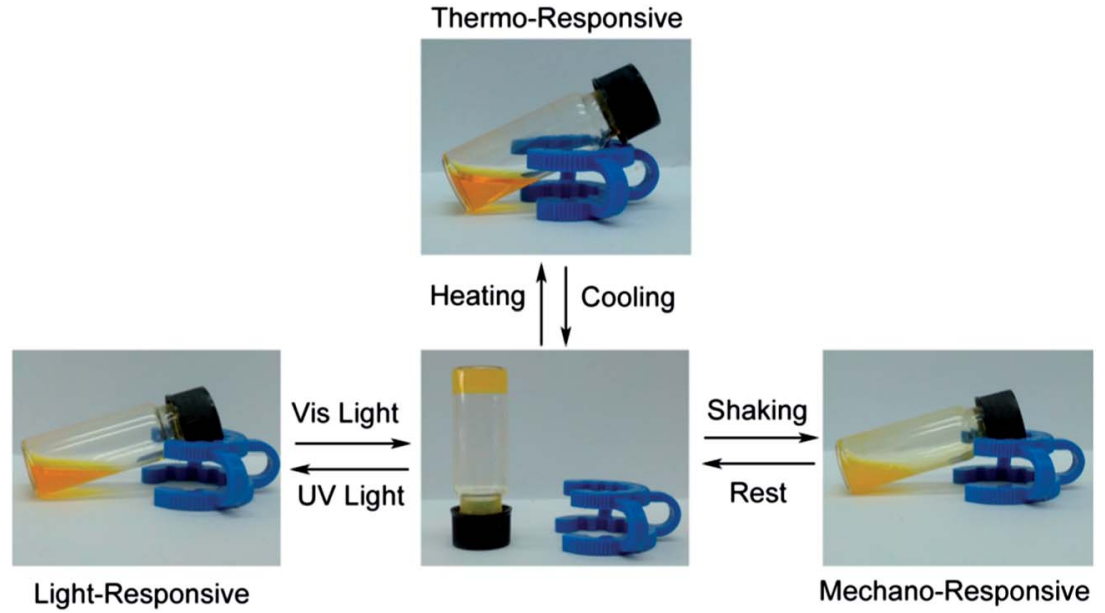

Fig. $2 \mathrm{C}_{8}$-Azo-TPC in $n$-dodecane (1.0 wt\%), multistimuli responsive organogels. 


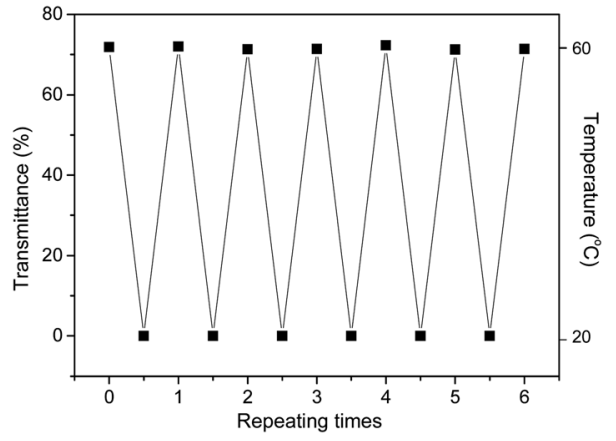

Fig. 3 Spectra of $\mathrm{C}_{8}$-Azo-TPC in $n$-dodecane at $1.0 \mathrm{wt} \%$ alternating temperature from $20{ }^{\circ} \mathrm{C}$ to $60^{\circ} \mathrm{C}$ to $20^{\circ} \mathrm{C}$ for six times cycle.

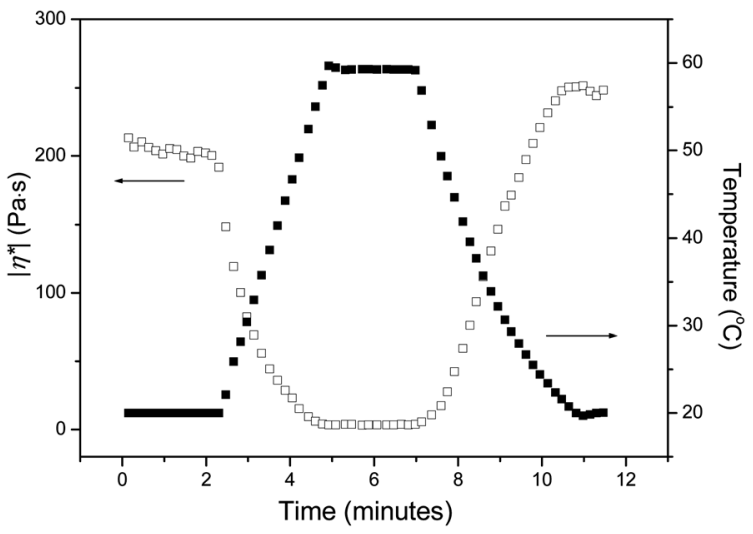

Fig. 4 Plot of viscosity against the temperature of $\mathrm{C}_{8}$-Azo-TPC in $n$-dodecane, (1.0 wt\%). ( $\square)\left|\eta^{*}\right|$ vs. time; ( $\square$ ) temperature vs. time.

to decrease. Upon a reduction in temperature, the viscosity was restored to the initial state, and the sample regained a gel-like viscous state. Fig. 5 shows $200 \times$ magnification polarizing optical microscope (POM) photographs of the $\mathrm{C}_{8}$-Azo-TPC gel in $n$-dodecane at $1.0 \mathrm{wt} \%$. The structure of both the gel $\left(20^{\circ} \mathrm{C}\right)$ and solution $\left(80^{\circ} \mathrm{C}\right)$ could clearly be observed. Bright areas in the POM images indicate the presence of a self-assembled macroscale $\mathrm{C}_{8}$-Azo-TPC domain potentially a liquid crystal like structure. Upon heating the polarization phenomenon mostly disappeared due to the loss of an organized network structure. Jung et al. reported similar behavior of organo gels, which were formed through intermolecular hydrogen bonds, $\pi-\pi$ stacking, and hydrophobic interaction. ${ }^{34}$

Variable temperature NMR spectroscopy was performed to investigate the gelation mechanism. In $\mathrm{CDCl}_{3}$, a non-gelling solvent for $\mathrm{C}_{8}$-Azo-TPC, the ${ }^{1} \mathrm{H}$ NMR the spectrum of $\mathrm{C}_{8}$-Azo-TPC contains only one set of peaks consistent with the proposed structure (Fig. S4 $\dagger$ ). In contrast, the ${ }^{1} \mathrm{H}$ NMR spectrum of $\mathrm{C}_{8^{-}}$ Azo-TPC in cyclohexane show multiple sets of peaks consistent with the coexistence of $\mathrm{C}_{8}$-Azo-TPC in two different states: an aggregate (peaks at $\delta 7.58,6.94,6.765 .42$ and $3.92 \mathrm{ppm}$ ) and single molecular state (peaks at $\delta 8.41,8.12,7.74,7.08,5.50$ and $4.02 \mathrm{ppm}$ ) (Fig. 6). The difference in chemical shift between protons in the gel and solution state are consistent with molecules associated by $\pi-\pi$ stacking and/or the hydrogen-bonding

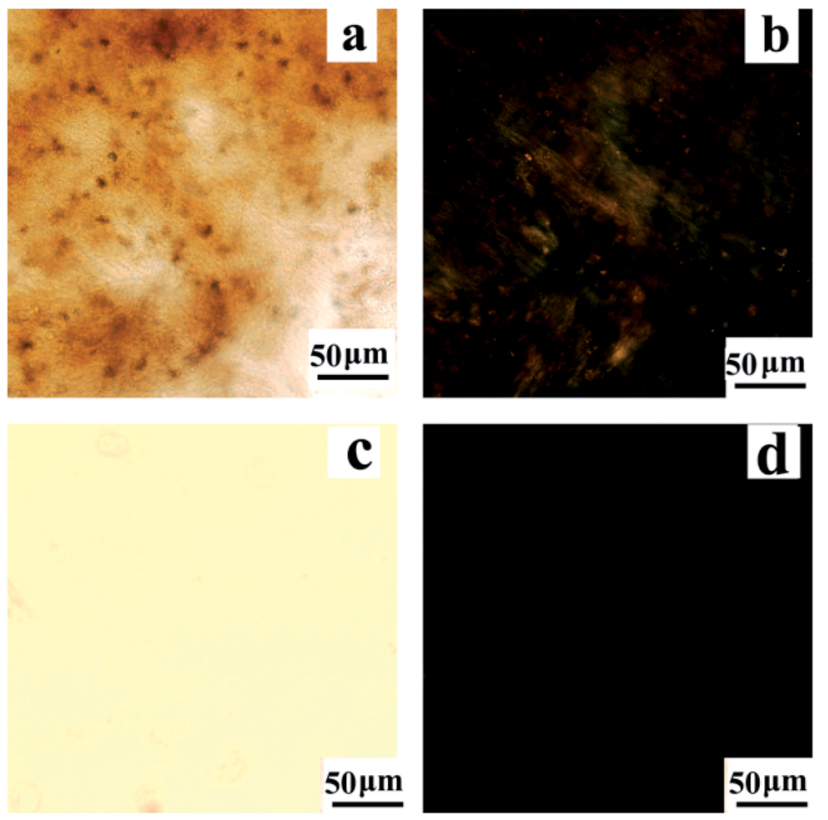

Fig. 5 POM images (200x magnification) for $\mathrm{C}_{8}$-Azo-TPC in $n$ dodecane $\left(1.0 \mathrm{wt} \%\right.$ ) under (a) visible light at $20^{\circ} \mathrm{C}$, (b) polarized light at $20^{\circ} \mathrm{C}$, (c) visible light at $80^{\circ} \mathrm{C}$, (d) polarized light at $80^{\circ} \mathrm{C}$, respectively.

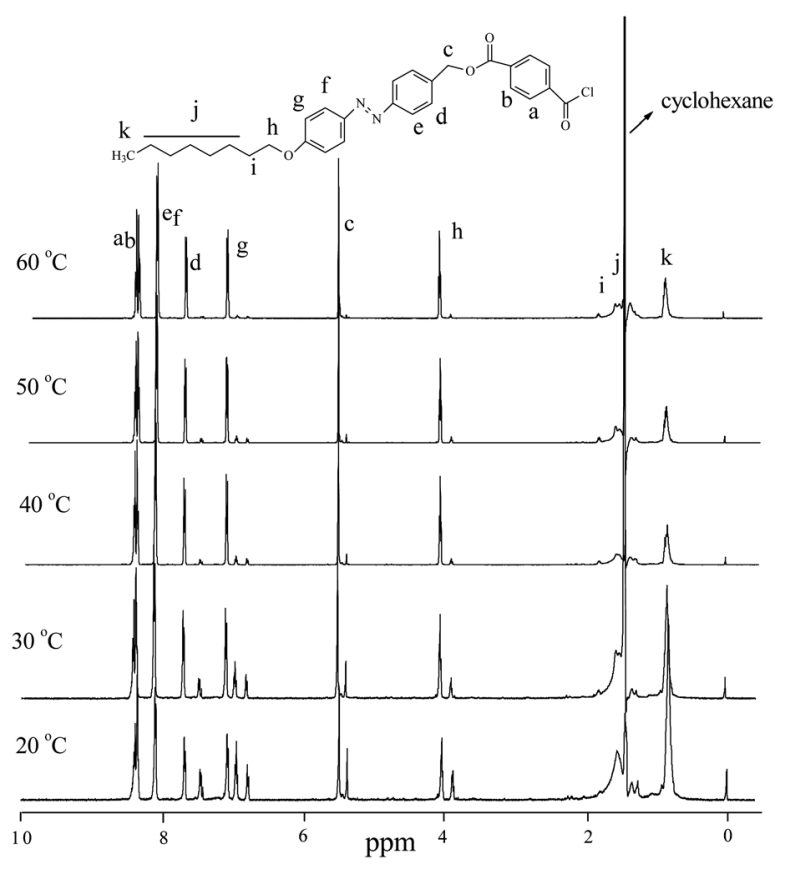

Fig. 6 Variable temperature ${ }^{1} \mathrm{H}$ NMR studies of the $\mathrm{C}_{8}$-Azo-TPC in cyclohexane (1.0 wt\%).

interactions and those of the free molecules, as also observed by Jung. ${ }^{34}$ Upon heating, the integral of the aggregate peaks decreased while the integral of the single molecular state peaks increased. Upon cooling, the reverse changes in peak integrals were observed. Although the integral of each peak changed depending on the temperature, the integration ratio between the aggregate and single molecule state was constant. The 
integration ratio of peaks at $\delta 3.90-4.10,5.35-5.60$, and $6.70-$ $8.50 \mathrm{ppm}$ corresponding to the alkyl chain methylene (h), benzyl methylene (c) and aromatic protons (a, b, e, d, g, f), respectively, remained at $1: 1: 6$ at all temperatures. Thus, the changes in the NMR spectrum with temperature are consistent with a gelator transitioning between the gel and solution state resulting from variation in the interactions between the molecules.

Synchrotron small angle X-ray scattering (SAXS) is a powerful method for exploring supramolecular structures. ${ }^{35}$ Further evidence for the thermally driven dissociation of the self assembled gels were obtained by SAXS analysis of the $\mathrm{C}_{8}$-AzoTPC gels. Scattering peaks in the SAXS spectrum of $\mathrm{C}_{8}$-Azo-TPC gel in $n$-dodecane $1.0 \mathrm{wt} \%$ at room temperature at $q=0.13 \AA^{-1}$ and $q=0.21 \AA^{-1}$ show the presence of a long-range ordered structure (Fig. S15 $\dagger$ ). However, this long-range order decreased as the sample was heated with the structure almost completely disappeared when the mixture was heated to $85{ }^{\circ} \mathrm{C}$.

\section{Shear induced sol/gel transitions}

In addition to temperature, the gel-sol phase transition could also be triggered by mechanical stimulus. For example, as shown in Fig. 2, at $1.0 \mathrm{wt} \%$ concentration, the gel of $\mathrm{C}_{8}$-Azo-TPC in $n$-dodecane became fluid as a result of vigorous shaking. This is consistent with partial disruption of the self-assembled structure. In this system, as indicated by the ${ }^{1} \mathrm{H}$ NMR analysis above, $\mathrm{C}_{8}$-Azo-TPC co-existed in both gel and solution at the same time. In order to obtain a visual insight into the morphologies, optical microscopy (OM) was used to observe the gel-sol phase transition (Fig. 7). In the gel state, as shown in Fig. 7a, the gel exhibited entangled and dense fibrous aggregates. Three dimensional fibrous networks containing fibers with widths of several micrometres and lengths of hundreds of micrometres were observed for the gel state. Similar fibrous structures were also observed in other azobenzene containing gels. ${ }^{21,19}$ These three dimensional networks, formed from self assembly of the $\mathrm{C}_{8}$-Azo-TPC into a fibrous structure, were responsible for the gelation. By applying force to the gel between microscope slides, the generated shear caused the gel to transform into vesicular structures (Fig. 7c). Following exposure to shear, Lee et al., also reported observing similar changes to the gel morphologies. ${ }^{36}$ These observations imply that without shear $\mathrm{C}_{8}$-Azo-TPC tended to aggregate into linear fibers due to $\pi-\pi$ interactions but formed vesicular structures under mechanical stimuli which overcame the relatively weak $\pi-\pi$ interactions. Thus, the major reason why the system acted as a fluid gel-sol mixture was associated with its aggregation mode. Fig. 7b shows the transition state between gel and sol which has not previously been reported. Owing to the mechanical stimuli, the fibrous aggregate was partially broken resulting in a mixture of both fibrous and vesicular structures. After resting for a few minutes, the micelles disappear and long microfibers slowly reformed. Regeneration of the fibers resulted in the reformation the gel state. The cycle involving vesicle-fiber transformation could be repeated many times (Fig. 2).

The mechano-responsive behavior of the organogels reported here was further investigated by rheological measurements. Plots of storage $\left(G^{\prime}\right)$ and loss $\left(G^{\prime \prime}\right)$ moduli monitored as functions of shear strain were shown in Fig. 8. It can be clearly observed that at initial strain values, the value of $G^{\prime}$ (about 4600 $\mathrm{Pa}$ ) was greater than $G^{\prime \prime}$ (about $1300 \mathrm{~Pa}$ ), indicating a dominant elastic characteristic of the sample. When the strain was initiated, the $G^{\prime}$ and $G^{\prime \prime}$ values of the gels decreased with increasing strain at $20{ }^{\circ} \mathrm{C}$. At low strain values, a sharp decrease of $G^{\prime}$ and $G^{\prime \prime}$ was observed, representing a partial breakup of the gel. Furthermore, a pronounced reduction was recorded for the storage modulus $\left(G^{\prime}\right)$, which dropped from around $4800 \mathrm{~Pa}$ to $600 \mathrm{~Pa}$. Specifically, the viscosity plummeted from about 1000 $\mathrm{Pa}$ s down to around $150 \mathrm{~Pa}$ s. Likewise a reduction was recorded for the loss modulus $\left(G^{\prime \prime}\right)$, which dropped from around $1400 \mathrm{~Pa}$ to $500 \mathrm{~Pa}$.

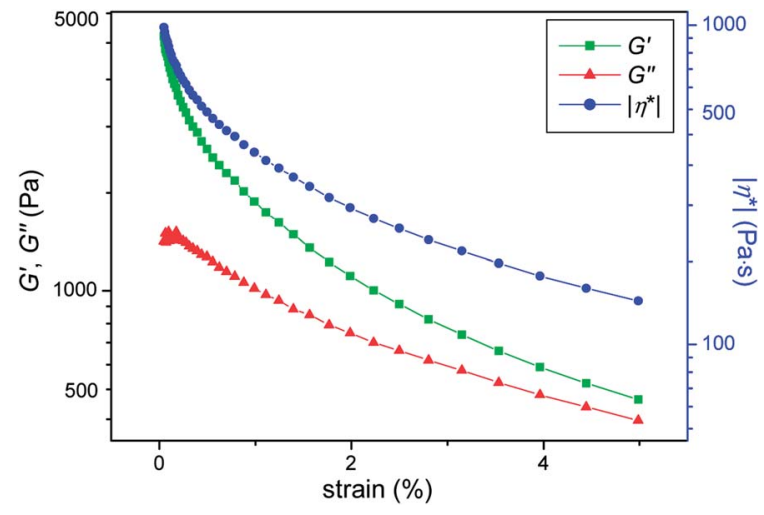

Fig. 8 Storage modulus $G^{\prime}$ and loss modulus $G^{\prime \prime}$ values of a $C_{8}$-AzoTPC organogel ( $n$-dodecane, $1.0 \mathrm{wt} \%$ ) on rheological experiments of strain sweep.
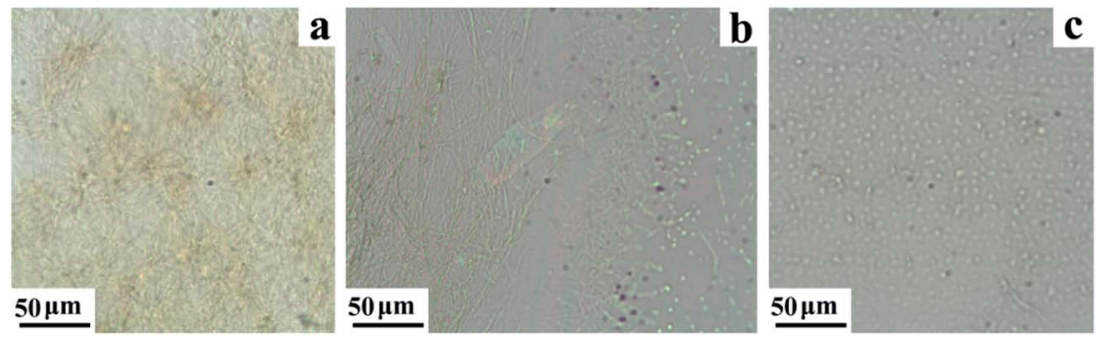

Fig. 7 Optical microscopy images (400x magnification) of $\mathrm{C}_{8}$-Azo-TPC in $n$-dodecane $\left(1.0\right.$ wt\%), $20{ }^{\circ} \mathrm{C}$, (a) gel; (b) transition between gel and sol; (c) sol. 


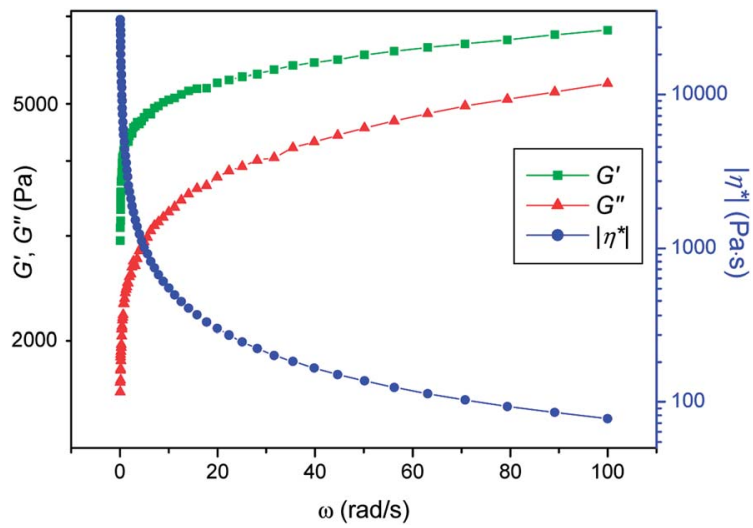

Fig. 9 Storage modulus $G^{\prime}$ and loss modulus $G^{\prime \prime}$ values of a $C_{8}$-AzoTPC organogel ( $n$-dodecane, $1.0 \mathrm{wt} \%$ ) on rheological experiments of frequency sweep

Frequency sweep experiments were conducted to study the mechanical properties of the gel. In all cases, the value of $G^{\prime \prime}$ was below the value of $G^{\prime}$ at all frequencies. Furthermore, the $G^{\prime}$ and $G^{\prime \prime}$ of both gels exhibited very strong frequency dependence in the range from 0.1 to $10 \mathrm{rad} \mathrm{s}^{-1}$ and minimal frequency dependence in the frequency range of $10-100 \mathrm{rad} \mathrm{s}^{-1}$. The results depicted in Fig. 9 showed that a pronounced increased was recorded for the storage modulus $\left(G^{\prime}\right)$, which increased from around $2600 \mathrm{~Pa}$ to $6000 \mathrm{~Pa}$, as well as the loss modulus $\left(G^{\prime \prime}\right)$, which increased from around $1500 \mathrm{~Pa}$ to $4600 \mathrm{~Pa}$. Specifically, the viscosity dropped markedly from about $2000 \mathrm{~Pa}$ s to around 10 Pa s. Similar thixotropic properties of the organogels in other solvents were also observed (e.g., see $n$-heptane results in the ESI section $\dagger$ ).

\section{Photo induced sol/gel transitions}

Azobenzene compounds are well-known for their reversible photoisomerization between the trans and cis forms under alternating UV and visible light irradiation. ${ }^{37}$ In order to investigate the light-responsive behavior of the $\mathrm{C}_{8}$-Azo-TPC in $n$-dodecane, UV/Vis spectroscopic studies of the compound were also performed. $\mathrm{C}_{8}$-Azo-TPC shows a broad absorption around $350 \mathrm{~nm}$ mainly due to the trans form of the azobenzene group. The resulting gels were subjected to UV irradiation at $365 \mathrm{~nm}$ for $20 \mathrm{~min}$ at $20^{\circ} \mathrm{C}$. The orange gels were found to collapse gradually and finally turned into transparent solutions. As shown in Fig. 10(a), UV irradiation results in the trans-cis isomerization, indicated by the decay of the maximum absorption band at around $350 \mathrm{~nm}$ and the generation of a new absorption at $446 \mathrm{~nm}$. Importantly, for practical applications, this photo-induced isomerization was reversible, as the azobenzene in cis form relaxes to trans form within a few minutes after exposure to visible light or more slowly in the dark. Fig. 10(b) showed that the cis to trans isomerisation was achieved by the subsequent irradiation of visible light.

Following a similar trend to the viscosity measurements, the dynamic changes to the storage modulus $\left(G^{\prime}\right)$ and the loss
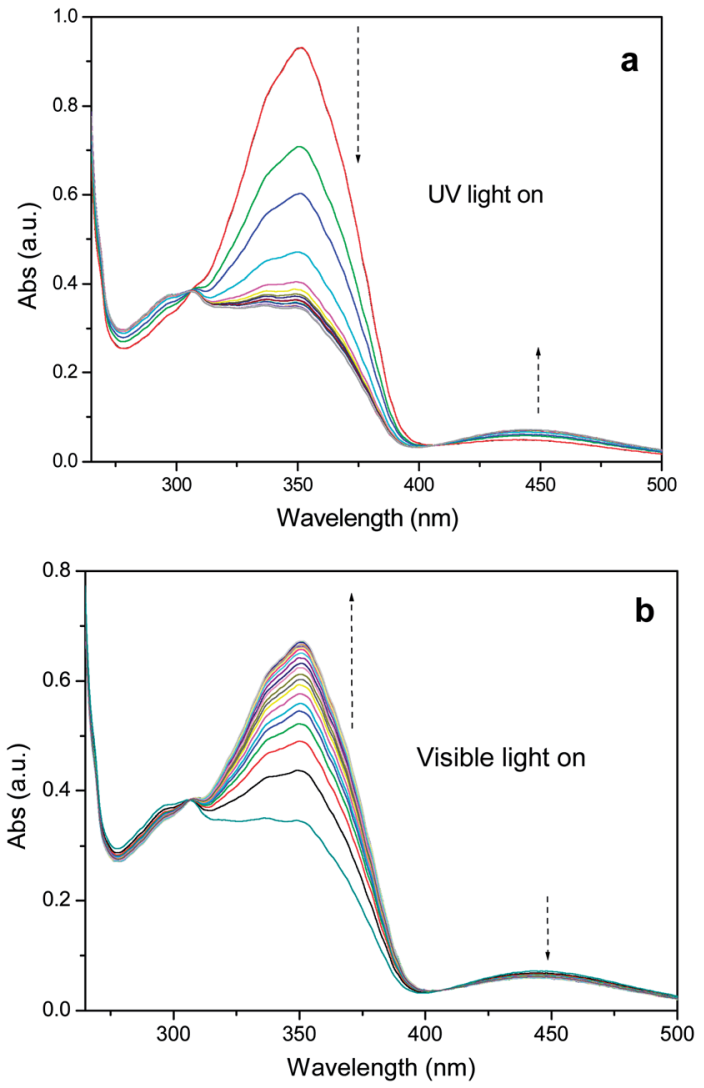

Fig. $10 \mathrm{C}_{8}$-Azo-TPC in $n$-dodecane at $20{ }^{\circ} \mathrm{C}(0.002$ wt\%), (a) change in absorption of UV-Vis spectra over time under UV light (365 nm, $3.8 \mathrm{~mW} \mathrm{~cm}^{-2}$ ); (b) change in absorption of UV-Vis spectra over time under visible light $\left(12.1 \mathrm{~mW} \mathrm{~cm}^{-2}\right)$.

modulus $\left(G^{\prime \prime}\right)$ with time were clearly observed under UV light exposure. Initially in the absence of UV exposure, the $G^{\prime}$ was greater than $G^{\prime \prime}$ indicating solid-like gel (i.e. beyond the $G^{\prime}, G^{\prime \prime}$ crossover point). However, during exposure of the gel to UV light (from $3 \mathrm{~min}$ ) a dramatic decrease of modulus was observed and a new plateau value was reached within 1 min (Fig. S13†). A corresponding change in viscosity was also observed (Fig. 11). The initial highly viscous gel changed to a low viscosity fluid under UV irradiation within one minute. After a period of UV exposure, a new steady state was established and the UV light was turned off. At the same time, visible light was turned on. The reversibility of the system was demonstrated by the rapid recovery of the rheological properties upon exposure to visible light. Viscosity was restored close to the initial state before UV light irradiation recommenced, and the sample regained a gellike viscous consistency. Such gel-sol phase transition by UV and visible light irradiation was reversible and again could be repeated many times (Fig. 2).

Real-time synchrotron SAXS measurements ${ }^{38,39}$ were also carried out to obtain structural information of the gelator in $n$ dodecane under different light exposure (Fig. 12). Initially, the SAXS spectrum of the gel was measured in the dark. Upon exposure to UV light, the SAXS peaks at $q=0.21 \AA^{-1}$ disappeared and peaks at $q<0.10 \AA^{-1}$ decreased significantly in intensity. When the UV light was switched off and the visible 


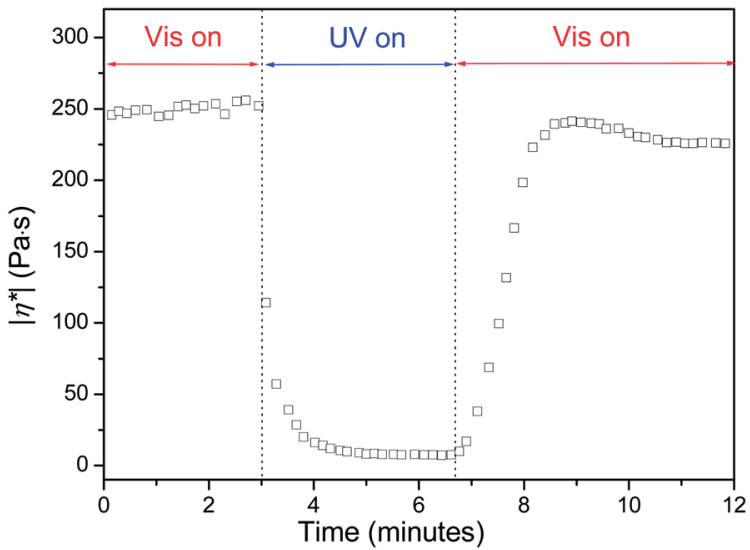

Fig. 11 Real-time photorheology measured over alternating UV ( $365 \mathrm{~nm}, 200 \mathrm{~mW} \mathrm{~cm}^{-2}$ ) and visible $\left(38 \mathrm{~mW} \mathrm{~cm}^{-2}\right.$ ) light irradiation for $\mathrm{C}_{8}$-Azo-TPC in $n$-dodecane $(1.0 \mathrm{wt} \%)$ at $20{ }^{\circ} \mathrm{C}$. The data were obtained at a constant frequency of $5 \mathrm{rad} \mathrm{s}^{-1}$ and a strain of $1.0 \%$.

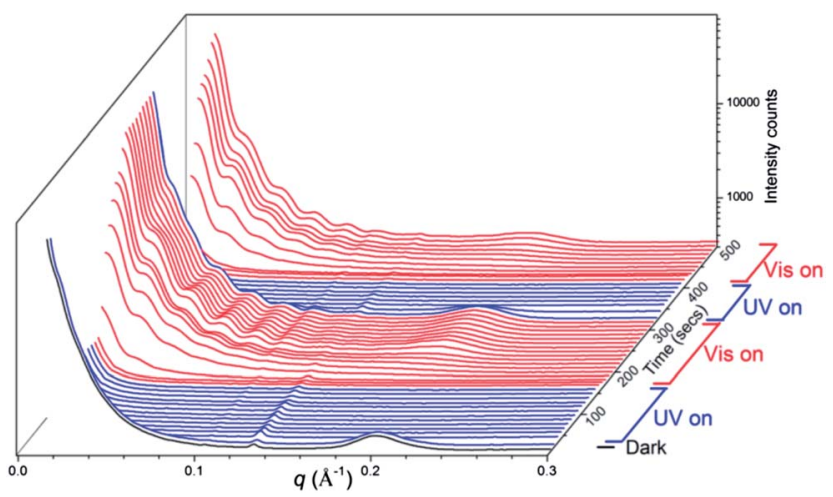

Fig. 12 Time resolved synchrotron SAXS patterns for the $\mathrm{C}_{8}$-Azo-TPC in $n$-dodecane (1.0 wt\%) upon UV light $\left(365 \mathrm{~nm}, 200 \mathrm{~mW} \mathrm{~cm}{ }^{-2}\right.$ ) exposure and visible light $\left(38 \mathrm{~mW} \mathrm{~cm}^{-2}\right)$ at $25^{\circ} \mathrm{C}$.

light turned on immediately, all the scattering peaks which disappeared under UV light re-appeared, indicating a reversible structural rearrangement. The first five diffraction peaks $\left(q<0.10 \AA^{-1}\right)$ indicated the formation of fiber aggregation in the gel and along with the POM measurements strongly suggest a liquid crystal like structure (Fig. 12 and S16†). ${ }^{40}$
Moreover, multiple cycles of this switching response can be achieved, demonstrating the reversibility of self-assembly in the system. The real time SAXS results confirmed that the changes in bulk properties result from the system transitioning between gel and sol states as the self-assembled structure forms and dissociates.

\section{Derivatives of $\mathrm{C}_{8}$-Azo-TPC}

$\mathrm{C}_{8}$-Azo-TPC contains a reactive group, an acyl chloride, which can remain active in the gel and opens the door to further synthetic elaborations (Scheme 2). In principle, the acyl chloride of $\mathrm{C}_{8}$-Azo-TPC can react with a number of nucleophiles enabling a large number of derivatives to be prepared with the potential to introduce many functionalities. For example, $\mathrm{C}_{8}$ Azo-TPC is a hydrophobic segment, which can react with hydrophilic polyethylene glycol methyl ether (MPEG) to form amphiphilic surfactants (Fig. S7†). These surfactants have similar multi-stimuli responsiveness with $\mathrm{C}_{8}$-Azo-TPC and can form a gel in some organic solvents. Not all compounds generated by reaction with $\mathrm{C}_{8}$-Azo-TPC with nucleophiles have multiple responsive behavior. For instance, the product from the reaction of $\mathrm{C}_{8}$-Azo-TPC with ethanol or water did not form a gel in organic solvents as shown in the Table 2. This may be because the products disrupt the appropriate intermolecular forces needed to form a gel. Carboxylic acid and ester groups may break the multiple non-covalent interactions such as hydrogen bonding, donor-acceptor and hydrophobic interactions between organic gels, thus losing the possibility of gelation.

Table 2 Results of gelation tests for $5 a-d^{a}$

\begin{tabular}{lllll}
\hline Solvent & $\mathbf{5 a}$ & $\mathbf{5 b}$ & $\mathbf{5 c}$ & $\mathbf{5 d}$ \\
\hline Water & I & I & I & I \\
Chloroform & S & S & S & S \\
Hexane & I & I & G & G \\
Benzene & I & I & S & S \\
Toluene & I & I & S & S \\
$n$-Dodecane & I & I & G & G \\
THF & S & S & S & S \\
Cyclohexane & I & I & G & G \\
$n$-Dodecane/EtOAc $=10 / 1$ & I & I & G & G
\end{tabular}

${ }^{a} 20{ }^{\circ} \mathrm{C}, 2.0 \mathrm{wt} \% ; \mathrm{G}=$ gel, $\mathrm{S}=$ clear solution after cooling, $\mathrm{I}=$ insoluble.<smiles>[R20]Oc1ccc(N=Nc2ccc(COC(=O)c3ccc(C(=O)OCc4ccc(C(=O)Cl)cc4)cc3)cc2)cc1</smiles>

$$
\begin{aligned}
& \mathrm{R}_{1}=\mathrm{CH}_{3}\left(\mathrm{CH}_{2}\right)_{6} \mathrm{CH}_{2}- \\
& \mathrm{R}_{2}=\text { (a) } \mathrm{H} \text {; (b) } \mathrm{CH}_{3} \mathrm{CH}_{2}-\text {; (c) } \mathrm{CH}_{3}\left(\mathrm{OCH}_{2} \mathrm{CH}_{2}\right)_{7} \text {; (d) } \mathrm{CH}_{3}\left(\mathrm{OCH}_{2} \mathrm{CH}_{2}\right)_{15}
\end{aligned}
$$




\section{Conclusions}

We have prepared a highly efficient and reactive super gelator containing an azobenzene group and studied its gel-forming properties. We found that some of these systems had good gelation properties in non-polar alkyl solvents due to reversible non-covalent self-assembly of $\mathrm{C}_{8}$-Azo-TPC into fibrous structures. The lowest CGCs can approach $0.08 \mathrm{wt} \%$ indicating that $\mathrm{C}_{8}$-Azo-TPC is a super gelator. This organogel exhibited multiple stimuli-responsive behaviors upon exposure to a number of environmental stimuli including temperature, light, and shear. Upon irradiation with UV light, the trans form of the $\mathrm{C}_{8}$-Azo-TPC rapidly photoisomerizes to its cis form resulting in rapid disruption of the gel. Application of heat or shear also resulted in sol state through disruption of the non-covalent interactions between the $\mathrm{C}_{8}$-Azo-TPC molecules. An insight into the morphologies of sol-gel transition was obtained by using optical microscopic images, variable temperature ${ }^{1} \mathrm{H}$ NMR spectroscopy and SAXS analysis. Importantly, $\mathrm{C}_{8}$-Azo-TPC may have many potential applications owing to its in-built active reactive group (benzoyl chloride). Adducts of $\mathrm{C}_{8}$-Azo-TPC with PEGs were also able to form gels in non-polar alkyl solvents. Through reaction of $\mathrm{C}_{8}$-Azo-TPC with a range of nucleophiles, a wide range of functionalities may be introduced opening the door to new applications for these active materials. The ability to control physical properties by external stimulus such as light, heat and shear may allow such smart materials to be used in a range of applications, such as hardeners of solvents and sensors.

\section{Acknowledgements}

The authors greatly acknowledge the support of this work by the National Natural Science Foundation of China (Grant no. 21204032) and Excellent Young Teacher Training Project of Jiangsu Province. SAXS/WAXS research was undertaken at the Australian Synchrotron, Victoria, Australia and the authors thank Dr Adrian Hawley for his assistance. The authors wish to thank Drs Keith McLean, Richard Evans and Colin Wood (CSIRO) for helpful discussions about the manuscript.

\section{Notes and references}

1 M. Suzuki and K. Hanabusa, Chem. Soc. Rev., 2010, 39, 455463.

2 A. Vintiloiu and J. Leroux, J. Controlled Release, 2008, 125, 179-192.

3 Z. I. Kalcioglu, R. A. Mrozek, R. Mahmoodian, M. R. Vanlandingham, J. L. Lenhart and K. J. Van Vliet, J. Biomech., 2013, 46, 1583-1591.

4 J. H. Jung, Y. Ono, K. Sakurai, M. Sano and S. Shinkai, J. Am. Chem. Soc., 2000, 122, 8648-8653.

5 W. Deng and D. H. Thompson, Soft Matter, 2010, 6, 18841887.

6 J. H. Jung, H. Kobayashi, M. Masuda, T. Shimizu and S. Shinkai, J. Am. Chem. Soc., 2001, 123, 8785-8789.
7 P. F. Duan, Y. G. Li, L. C. Li, J. G. Deng and M. H. Liu, J. Phys. Chem. B, 2011, 115, 3322-3329.

8 X. Ran, H. T. Wang, P. Zhang, B. L. Bai, C. X. Zhao, Z. X. Yu and M. Li, Soft Matter, 2011, 7, 8561-8566.

9 Y. F. Zhou, Prog. Chem., 2011, 23, 125-135.

10 S. Yagai, T. Nakajima, K. Kishikawa, S. Kohmoto, T. Karatsu and A. Kitamura, J. Am. Chem. Soc., 2005, 127, 1113411139.

11 Y. P. Wu, S. Wu, G. Zou and Q. J. Zhang, Soft Matter, 2011, 7, 9177-9183.

12 F. Delbecq, N. Kaneko, H. Endo and T. Kawai, J. Colloid Interface Sci., 2012, 384, 94-98.

13 N. S. Kumar, S. Varghese, G. Narayan and S. Das, Angew. Chem., Int. Ed., 2006, 45, 6317-6321.

14 S. Kume, K. Kuroiwa and N. Kimizuka, Chem. Commun., 2006, 2442-2444.

15 A. Dawn, N. Fujita, S. Haraguchi, K. Sada and S. Shinkai, Chem. Commun., 2009, 2100-2102.

16 J. Mamiya, K. Kanie, T. Hiyama, T. Ikeda and T. Kato, Chem. Commun., 2002, 1870-1871.

17 K. Tatsuya, F. Norifumi and S. Seiji, Chem. Lett., 2008, 37, 912-913.

18 J. J. D. de Jong, L. N. Lucas, R. M. Kellogg, J. H. van Esch and B. L. Feringa, Science, 2004, 304, 278-281.

19 Y. Takashima, S. Hatanaka, M. Otsubo, M. Nakahata, T. Kakuta, A. Hashidzume, H. Yamaguchi and A. Harada, Nat. Commun., 2012, 3, 1270.

20 T. Jiao, Y. Wang, Q. Zhang, J. Zhou and F. Gao, Nanoscale Res. Lett., 2013, 8, 160.

21 Z. X. Liu, Y. Feng, Z. C. Yan, Y. M. He, C. Y. Liu and Q. H. Fan, Chem. Mater., 2012, 24, 3751-3757.

22 C. Wang, Q. Chen, F. Sun, D. Zhang, G. Zhang, Y. Huang, R. Zhao and D. Zhu, J. Am. Chem. Soc., 2010, 132, 30923096.

23 T. Zhang and Q. Guo, Chem. Commun., 2013, 49, 5076-5078.

24 T. Haino and H. Saito, Aust. J. Chem., 2010, 63, 640-645.

25 P. Xue, J. Sun, Q. Xu, R. Lu, M. Takafuji and H. Ihara, Org. Biomol. Chem., 2013, 11, 1840-1847.

26 Y. F. Zhou, M. Xu, T. Yi, S. Z. Xiao, Z. G. Zhou, F. Y. Li and C. H. Huang, Langmuir, 2007, 23, 202-208.

27 M. Zinic, F. Vogtle and F. Fages, Top. Curr. Chem., 2005, 256, 39-76.

28 T. F. Jiao, Y. J. Wang, F. Q. Gao, J. X. Zhou and F. M. Gao, Prog. Nat. Sci., 2012, 22, 64-70.

29 W. D. Chen, W. T. Gong, J. W. Ye, Y. Lin and G. L. Ning, RSC Adv., 2012, 2, 809-811.

30 B. G. Bag, S. K. Dinda, P. P. Dey, V. A. Mallia and R. G. Weiss, Langmuir, 2009, 25, 8663-8671.

31 K. Tiefenbacher, H. Dube, D. Ajami and J. Rebek, Jr, Chem. Commun., 2011, 47, 7341-7343.

32 R. Rajaganesh, A. Gopal, T. M. Das and A. Ajayaghosh, Org. Lett., 2012, 14, 748-751.

33 M. A. K. Murata, T. Suzuki, T. Harada, H. Kawabata, T. Komori, F. Ohseto, K. Ueda and S. Shinkai, J. Am. Chem. Soc., 1994, 116, 6664-6676.

34 S. J. Lee, S. S. Lee, J. S. Kim, J. Y. Lee and J. H. Jung, Chem. Mater., 2005, 17, 6517-6520. 
35 H. Takeno, A. Maehara, D. Yamaguchi and S. Koizumi, J. Phys. Chem. B, 2012, 116, 7739-7745.

36 S. Lee, S. Oh, J. Lee, Y. Malpani, Y. S. Jung, B. Kang, J. Y. Lee, K. Ozasa, T. Isoshima, S. Y. Lee, M. Hara, D. Hashizume and J. M. Kim, Langmuir, 2013, 29, 5869-5877.

37 Y. F. Zhou, M. Xu, J. C. Wu, T. Yi, J. T. Han, S. Z. Xiao, F. Y. Li and C. H. Huang, J. Phys. Org. Chem., 2008, 21, 338-343.
38 S. Peng, Q. Guo, T. C. Hughes and P. Hartley, Macromolecules, 2011, 44, 3007-3015.

39 S. Peng, Q. Guo, T. C. Hughes and P. Hartley, Soft Matter, 2012, 8, 10493-10501.

40 K. Sakurai, Y. Jeong, K. Koumoto, A. Friggeri, O. Gronwald, S. Sakurai, S. Okamoto, K. Inoue and S. Shinkai, Langmuir, 2003, 19, 8211-8217. 